\title{
Pulmonary Function Difference in Sasang Constitutional Types
}

\author{
Jiwon Yoon, ${ }^{1}$ Chae Hun Leem, ${ }^{2}$ and Jong Yeol Kim $\mathbb{D D}^{1}$ \\ ${ }^{1}$ KM Fundamental Research Division, Korea Institute of Oriental Medicine, 1672 Yuseong-daero, Yuseong-gu, \\ Daejeon 34054, Republic of Korea \\ ${ }^{2}$ Department of Physiology, University of Ulsan College of Medicine, 88 Olympic-ro 43-gil, Songpa-gu, Seoul 05505, Republic of Korea
}

Correspondence should be addressed to Jong Yeol Kim; ssmed@kiom.re.kr

Received 22 January 2018; Accepted 18 March 2018; Published 2 May 2018

Academic Editor: Carmen Mannucci

Copyright (C) 2018 Jiwon Yoon et al. This is an open access article distributed under the Creative Commons Attribution License, which permits unrestricted use, distribution, and reproduction in any medium, provided the original work is properly cited.

The purpose of this study was to determine the differences in pulmonary function among Sasang constitutional types in young adults. The Sasang Constitutional Analysis Tool (SCAT), pulmonary function tests (PFTs), and cardiopulmonary exercise tests were conducted in 417 participants from 2009 to 2015. Subjects with the Tae-Eum (TE) type had significantly higher inspiratory capacity (IC) and inspiratory reserve volume (IRV) values than those with the So-Yang (SY) and So-Eum (SE) types $(P<0.0001)$. The TE and SY types showed higher forced vital capacity (FVC) and forced expiratory volume in 1 sec $\left(\mathrm{FEV}_{1}\right)$ values than the SE type $(P<0.0001)$. An increase in IRV and a decrease in expiratory reserve volume (ERV) in TE type males remained even after adjusting for covariate factors. These results indicate that young adults with the TE type have weaker lung function than those with the other constitutional types, suggesting its innate physiological pulmonary features.

\section{Introduction}

Sasang Constitutional Medicine (SCM) is a traditional Korean medicine created by Lee Je-ma (1837-1900) at the end of the 19th century [1]. SCM categorizes humans into four types: So-Eum (SE), So-Yang (SY), Tae-Eum (TE), and TaeYang (TY). The physical, psychological, physiological, and pathological characteristics of each constitution differ, and treatment methods such as drugs and acupuncture should also differ according to the constitution [2]. Several crosssectional studies have shown that the prevalence of chronic diseases, such as hypertension [3], diabetes [4], insulin resistance [5], and metabolic syndrome [6], varies depending on the constitution and that the Sasang constitution is an independent risk factor for these diseases. Particularly, it is reported that the risk of chronic illness is higher in subjects with the TE type than in those with other constitutions [7]. The TE type can be vulnerable to various diseases as a result of constitutional characteristics [8]. The TE type is prone to have a higher body mass index (BMI) and prevalence of abdominal obesity than the other types [9]. According to the SCM visceral theory, the TE type is hypothesized to have a hypoactive-lung and hyperactive-liver system, indicating relatively low energy consumption function and relatively developed energy storage function [10]. Studies supporting the hypoactive-lung theory report low mitochondrial metabolism [11], attenuated cellular energy metabolism [12], and reduced adenosine triphosphate- (ATP-) linked oxygen consumption rates [13] of the TE types.

The pulmonary function test (PFT) is widely used in clinical practice to screen for the presence or absence of pulmonary dysfunction [14]. If measured values, such as forced vital capacity (FVC) and forced expiratory volume in $1 \mathrm{sec}\left(\mathrm{FEV}_{1}\right)$, are decreased, it is defined as pulmonary dysfunction [15]. Several studies in multiple populations have shown that pulmonary dysfunction is closely related to cardiovascular disease $[16,17]$ and is associated with cardiovascular risk factors such as hypertension [18], diabetes [19], and dyslipidemia [20]. Recent studies have shown that metabolic syndrome, consisting of increased blood pressure, insulin resistance, dyslipidemia, and abdominal obesity, also significantly increases the risk of pulmonary dysfunction [21, 22]. However, studies on pulmonary function according to Sasang constitution have not been published, except for those on chronic obstructive pulmonary disease [23], impaired lung function and metabolic syndrome [24], and the comparison of pulmonary function in middle-aged participants [25]. 
The relationship between Sasang constitution and pulmonary dysfunction has not yet been clarified. There have been few attempts at scientific and comprehensive pathological interpretation. As the risk of metabolic diseases increases, the importance of the TE type's physiological interpretation also increases.

\section{Methods}

2.1. Participants. This cross-sectional study was conducted from 2009 to 2015 . All of the questionnaire data and clinical data, including Sasang constitutional type (SCT) and PFT, were compiled from the Korea Constitutional Multicenter Bank (KCMB) of the Korea Institute of Oriental Medicine (KIOM). Using this resource, we collected questionnaire data on 417 subjects who were recruited at Asan Medical Center. The present study population comprised a population-based sample selected from healthy subjects recruited through advertisements at Asan Medical Center. Twenty-six subjects who did not complete the PFT were excluded from the analysis. After applying these exclusions, a total of 391 individuals were analyzed. This study was approved by the Institutional Review Board of Asan Medical Center (IRB number: 20090566). All participants agreed to join this study, and written informed consent for participation was obtained.

2.2. Sasang Constitutional Analysis Tool (SCAT). The determination of SCT was performed using the SCAT developed by the KIOM [26]. Facial images, body shapes, voice analysis, and questionnaire responses on personality and physiological symptoms were integrated into a multinomial logistic regression analysis. The diagnostic accuracy of SCAT has been reported to be higher than that of QSCC II, which is commonly used for the diagnosis of SCT [27].

2.3. PFT and Cardiopulmonary Exercise Test. The PFT was performed using a Vmax 229 Pulmonary Function/Cardiopulmonary Exercise Testing Instrument (SensorMedics, Yorba Linda, CA, USA). FVC and $\mathrm{FEV}_{1}$ were measured at rest. $\mathrm{FEV}_{1} / \mathrm{FVC}$ was calculated as $\mathrm{FEV}_{1}$ divided by FVC. Total lung capacity and its subdivisions were measured by the nitrogen washout method with the Vmax 229. PFT was performed in accordance with recommended standards [28]. Maximum oxygen consumption $\left(\mathrm{VO}_{2 \max }, \mathrm{mL} / \mathrm{kg} / \mathrm{min}\right)$, a measure of cardiorespiratory fitness, was recorded using a Vmax ENCORE 29c indirect calorimeter (SensorMedics) during exercise testing on a treadmill following a standard Bruce protocol [29]. The anaerobic threshold (AT) was determined by the V-slope method and was then confirmed. The time duration from the starting point to the time when the participants demanded to stop was defined as the exercise time (sec).

2.4. Anthropometric Data and Biochemical Measurements. BMI was calculated as weight divided by height squared. Waist circumference $(\mathrm{cm})$ was measured at the narrowest point between the lower rib and the iliac crest. Blood pressure was measured with a standard mercury sphygmomanometer on the nondominant arm. Blood samples were analyzed at Seoul Clinical Laboratories (Seoul, South Korea) to determine the levels of fasting plasma glucose, insulin, triglycerides (TGs), and high-density lipoprotein (HDL) cholesterol.

2.5. Statistical Analysis. All statistical analyses were performed with SPSS Statistics ${ }^{\circledR}$ version 23 (SPSS, IBM Corp, Armonk, NY, USA). One-way analysis of variance (ANOVA) was conducted to evaluate differences in the general characteristics and cardiorespiratory values across SCTs. Bonferroni's post hoc test was performed for multiple comparisons. The PFT and cardiopulmonary fitness data were compared among SCTs using analysis of covariance (ANCOVA) while adjusting for sex, age, height, weight, and presence of diabetes mellitus (factors that are known to affect PFT values). The participants were defined as having diabetes mellitus if a fasting glucose level exceeded $\geq 126 \mathrm{mg} / \mathrm{dL}$ or 2 -hour plasma glucose exceeded $\geq 200 \mathrm{mg} / \mathrm{dL}$. All $P$ values $<0.05$ were considered statistically significant.

\section{Results}

3.1. General Characteristics of Participants. The general characteristics of the participants are shown in Table 1. Overall, height was higher in subjects with the TE type. However, no significant difference was found when stratified by gender. Except for fasting glucose, parameters related to metabolic syndrome, such as weight, BMI, waist circumference, fasting insulin, TGs, and blood pressure, were significantly higher in subjects with the TE type. When stratified by gender, no significant difference was found in either systolic blood pressure (SBP) or diastolic blood pressure (DBP).

3.2. PFT Results among SCTs (ANOVA). Overall, the results of the PFT showed that subjects with the TE type had significantly higher IC and IRV values than those with the SE and SY types. Vital capacity (VC), FVC, and FEV 1 were lower in subjects with the SE type than in those with the TE and SY types. When stratified by gender, male TE participants had higher inspiratory capacity (IC) and inspiratory reserve volume (IRV) values and lower expiratory reserve volume (ERV) values than those with the other types. Female TE and SY participants had higher VC, inspiratory capacity (IC), and FVC values than those with the SE types.

Interestingly, FVC and $\mathrm{FEV}_{1}$ showed a similar trend in the TE and SY groups despite the difference in BMI and TE groups were higher in the SE group. When stratified by gender, IC, ERV, and IRV showed a similar trend despite the difference in BMI; male TE participants had higher IC and IRV values and lower ERV values than the SE type. In females, this tendency was maintained; TE and SY participants had similar VC, IC, and FVC values, which were higher than in the SE participants (Table 2).

3.3. PFT Results among SCTs (ANCOVA). Unlike the ANOVA analysis, in ANCOVA in which the variables (age, height, weight, and presence of diabetes mellitus) that can affect the PFT were adjusted, the influence of the significant variables from the ANOVA almost disappeared. 
TABLE 1: General characteristics of participants among the Sasang constitutional types.

\begin{tabular}{|c|c|c|c|c|c|}
\hline Variable & $\mathrm{TE}$ & SE & SY & $P$ value & Post hoc \\
\hline $\begin{array}{l}\text { Total } \\
\text { Number of cases }\end{array}$ & 153 & 72 & 166 & & \\
\hline Age (yr) & $31.49 \pm 6.84$ & $32 \pm 7.12$ & $29.83 \pm 6.63$ & 0.0287 & \\
\hline Height $(\mathrm{cm})$ & $168.77 \pm 8.7$ & $164.48 \pm 8.62$ & $167.22 \pm 8.6$ & 0.0025 & $\mathrm{TE}>\mathrm{SE}$ \\
\hline Weight (kg) & $73.91 \pm 12.08$ & $54.53 \pm 8.07$ & $62.62 \pm 10.04$ & $<0.0001$ & $\mathrm{TE}>\mathrm{SY}>\mathrm{SE}$ \\
\hline BMI (kg/m2) & $25.84 \pm 2.97$ & $20.06 \pm 1.55$ & $22.26 \pm 2.02$ & $<0.0001$ & $\mathrm{TE}>\mathrm{SY}>\mathrm{SE}$ \\
\hline SBP & $109.61 \pm 13.09$ & $102.35 \pm 11.89$ & $104.52 \pm 12.35$ & $<0.0001$ & $\mathrm{TE}>\mathrm{SE}, \mathrm{SY}$ \\
\hline DBP & $68.46 \pm 9.27$ & $63.79 \pm 9.2$ & $64.25 \pm 8.31$ & $<0.0001$ & $\mathrm{TE}>\mathrm{SE}, \mathrm{SY}$ \\
\hline Waist & $88.58 \pm 8$ & $73.83 \pm 5.46$ & $78.33 \pm 6.28$ & $<0.0001$ & $\mathrm{TE}>\mathrm{SY}>\mathrm{SE}$ \\
\hline Fasting insulin (uU/mL) & $9.72 \pm 7.19$ & $5.46 \pm 3.36$ & $6.39 \pm 5.18$ & $<0.0001$ & TE $>$ SE, SY \\
\hline $\mathrm{TG}(\mathrm{mg} / \mathrm{dL})$ & $111.24 \pm 83.41$ & $70.65 \pm 39.15$ & $80.74 \pm 43.78$ & $<0.0001$ & $\mathrm{TE}>\mathrm{SE}, \mathrm{SY}$ \\
\hline Fasting glucose (mg/dL) & $88.23 \pm 25.92$ & $85.63 \pm 18.53$ & $83.92 \pm 16.48$ & 0.1872 & \\
\hline HDL & $48.99 \pm 17.84$ & $57.87 \pm 19.02$ & $55.27 \pm 18.46$ & $<0.0001$ & TE $>$ SE, SY \\
\hline $\begin{array}{l}\text { Male } \\
\text { Number of cases }\end{array}$ & 89 & 26 & 89 & & \\
\hline Age (yr) & $30.58 \pm 6.75$ & $30.54 \pm 6.08$ & $29.42 \pm 6$ & 0.4355 & \\
\hline Height (cm) & $174.59 \pm 5.27$ & $173.04 \pm 5.71$ & $173.44 \pm 5.49$ & 0.2611 & \\
\hline Weight (kg) & $81.02 \pm 9.45$ & $62.5 \pm 6.19$ & $70.4 \pm 6.49$ & $<0.0001$ & $\mathrm{TE}>\mathrm{SY}>\mathrm{SE}$ \\
\hline BMI $(\mathrm{kg} / \mathrm{m} 2)$ & $26.56 \pm 2.68$ & $20.83 \pm 1.22$ & $23.39 \pm 1.74$ & $<0.0001$ & $\mathrm{TE}>\mathrm{SY}>\mathrm{SE}$ \\
\hline SBP & $113.09 \pm 12.2$ & $108.62 \pm 11.05$ & $110.93 \pm 11.8$ & 0.1932 & \\
\hline DBP & $70.17 \pm 9.84$ & $67.73 \pm 10.3$ & $67.24 \pm 8.53$ & 0.1018 & \\
\hline Waist & $90.9 \pm 7.24$ & $75.91 \pm 4.97$ & $81.64 \pm 5.21$ & $<0.0001$ & $\mathrm{TE}>\mathrm{SY}>\mathrm{SE}$ \\
\hline Fasting insulin (uU/mL) & $9.79 \pm 6.28$ & $4.57 \pm 2.05$ & $6.75 \pm 4.85$ & $<0.0001$ & TE $>$ SE, SY \\
\hline $\mathrm{TG}(\mathrm{mg} / \mathrm{dL})$ & $115.56 \pm 66.97$ & $87.07 \pm 52.23$ & $91.64 \pm 51.67$ & 0.0116 & $\mathrm{TE}>\mathrm{SY}$ \\
\hline Fasting glucose (mg/dL) & $86.22 \pm 22.85$ & $88.02 \pm 20.09$ & $85.18 \pm 17.15$ & 0.8123 & \\
\hline $\mathrm{HDL}$ & $44.42 \pm 16.74$ & $53.56 \pm 17.5$ & $49.89 \pm 16.02$ & 0.0174 & $\mathrm{TE}<\mathrm{SY}$ \\
\hline $\begin{array}{l}\text { Female } \\
\text { Number of cases }\end{array}$ & 64 & 46 & 77 & & \\
\hline Age (yr) & $32.75 \pm 6.82$ & $32.83 \pm 7.58$ & $30.3 \pm 7.3$ & 0.0707 & \\
\hline Height (cm) & $160.68 \pm 5.43$ & $159.63 \pm 5.72$ & $160.02 \pm 5.29$ & 0.5867 & \\
\hline Weight (kg) & $64.03 \pm 7.53$ & $50.02 \pm 4.91$ & $53.63 \pm 4.14$ & $<0.0001$ & $\mathrm{TE}>\mathrm{SY}>\mathrm{SE}$ \\
\hline BMI (kg/m2) & $24.84 \pm 3.09$ & $19.62 \pm 1.55$ & $20.95 \pm 1.44$ & $<0.0001$ & $\mathrm{TE}>\mathrm{SY}>\mathrm{SE}$ \\
\hline SBP & $104.77 \pm 12.82$ & $98.8 \pm 10.94$ & $97.1 \pm 8.11$ & $<0.0001$ & $\mathrm{TE}>\mathrm{SE}, \mathrm{SY}$ \\
\hline DBP & $66.08 \pm 7.89$ & $61.57 \pm 7.78$ & $60.81 \pm 6.57$ & $<0.0001$ & $\mathrm{TE}>\mathrm{SE}, \mathrm{SY}$ \\
\hline Waist & $85.35 \pm 7.93$ & $72.65 \pm 5.41$ & $74.51 \pm 5.17$ & $<0.0001$ & TE $>$ SE, SY \\
\hline Fasting insulin (uU/mL) & $9.63 \pm 8.34$ & $5.97 \pm 3.84$ & $5.98 \pm 5.54$ & 0.0011 & $\mathrm{TE}>\mathrm{SE}, \mathrm{SY}$ \\
\hline $\mathrm{TG}(\mathrm{mg} / \mathrm{dL})$ & $105.24 \pm 102.26$ & $61.37 \pm 25.68$ & $68.15 \pm 27.75$ & 0.0004 & $\mathrm{TE}>\mathrm{SE}, \mathrm{SY}$ \\
\hline Fasting glucose (mg/dL) & $91.01 \pm 29.64$ & $84.28 \pm 17.67$ & $82.46 \pm 15.66$ & 0.0616 & \\
\hline HDL & $55.34 \pm 17.48$ & $60.3 \pm 19.59$ & $61.5 \pm 19.22$ & 0.1365 & \\
\hline
\end{tabular}

Data are presented as the mean \pm standard deviation. $P$ value: ANOVA result. TE: Tae-Eum, SE: So-Eum, SY: So-Yang, BMI: body mass index, SBP: systolic blood pressure, DBP: diastolic blood pressure, TG: triglyceride, and HDL: high-density lipoprotein.

ANCOVA revealed no significant difference in any PFT variables except for $\mathrm{FEV}_{1}$, although there was a trend towards higher IRV and lower ERV and FVC values in subjects with the TE than in other types.

According to the analysis stratified by gender, there was no significant difference in any variable in males. However, although statistical significance was not achieved among the constitutional types, there was a tendency for male TE participants to have lower tidal volume (VT), VC, ERV, and FVC values and higher IC and IRV values than the other constitutional types.
In females, $\mathrm{VC}$ and exercise time were significantly lower in SE participants than in SY participants. Additionally, ERV was higher and IRV was lower in TE participants, in contrast to the total and male results (Table 3 ).

\section{Discussion}

Among the SCTs, the constitution that is profoundly related to pulmonary function is the TE type. Subjects with the TE type have weak pulmonary function and strong liver function compared to the other constitutions [10]. The purpose of this 
TABLE 2: Results of pulmonary function test among Sasang constitutional type (ANOVA).

\begin{tabular}{|c|c|c|c|c|c|}
\hline Variables & TE & SE & SY & $P$ value & Post hoc \\
\hline $\begin{array}{l}\text { Total } \\
\text { Number of subjects }\end{array}$ & 153 & 72 & 166 & & \\
\hline VT, liters & $0.66 \pm 0.28$ & $0.58 \pm 0.25$ & $0.66 \pm 0.30$ & 0.0543 & \\
\hline VC, liters & $4.34 \pm 0.94$ & $3.79 \pm 1.06$ & $4.25 \pm 0.93$ & $<0.0001$ & $\mathrm{TE}>\mathrm{SE}, \mathrm{SY}>\mathrm{SE}$ \\
\hline IC, liters & $2.85 \pm 0.74$ & $2.27 \pm 0.59$ & $2.64 \pm 0.66$ & $<0.0001$ & $\mathrm{TE}>\mathrm{SY}>\mathrm{SE}$ \\
\hline ERV, liters & $1.49 \pm 0.52$ & $1.53 \pm 0.60$ & $1.61 \pm 0.52$ & 0.1574 & \\
\hline IRV, liters & $2.20 \pm 0.70$ & $1.69 \pm 0.53$ & $1.98 \pm 0.61$ & $<0.0001$ & $\mathrm{TE}>\mathrm{SY}>\mathrm{SE}$ \\
\hline FVC, liters & $4.37 \pm 0.93$ & $3.85 \pm 1.00$ & $4.30 \pm 0.95$ & $<0.0001$ & $\mathrm{TE}>\mathrm{SE}, \mathrm{SY}>\mathrm{SE}$ \\
\hline $\mathrm{FEV}_{1}$, liters & $3.52 \pm 0.75$ & $3.11 \pm 0.81$ & $3.51 \pm 0.79$ & $<0.0001$ & $\mathrm{TE}>\mathrm{SE}, \mathrm{SY}>\mathrm{SE}$ \\
\hline $\mathrm{FEV}_{1} / \mathrm{FVC}(\%)$ & $81.12 \pm 8.08$ & $81.06 \pm 9.11$ & $82.02 \pm 8.46$ & 0.6973 & \\
\hline $\mathrm{VO}_{2 \max }(\mathrm{ml} / \mathrm{kg} / \mathrm{min})$ & $39.82 \pm 7.21$ & $40.37 \pm 7.39$ & $42.56 \pm 7.52$ & 0.0031 & $\mathrm{SY}>\mathrm{TE}$ \\
\hline $\mathrm{AT}(\mathrm{mL} /(\mathrm{kg} \cdot \mathrm{min}))$ & $22.56 \pm 3.85$ & $23.07 \pm 5.32$ & $23.32 \pm 4.58$ & 0.3117 & \\
\hline Exercise time (sec) & $643.21 \pm 86.77$ & $619.88 \pm 95.59$ & $672.67 \pm 89.82$ & $<0.0001$ & $\mathrm{SY}>\mathrm{SE}, \mathrm{SY}>\mathrm{TE}$ \\
\hline $\begin{array}{l}\text { Male } \\
\text { Number of subjects }\end{array}$ & 89 & 26 & 89 & & \\
\hline VT, liters & $0.72 \pm 0.29$ & $0.71 \pm 0.27$ & $0.73 \pm 0.32$ & 0.9788 & \\
\hline VC, liters & $4.95 \pm 0.71$ & $4.86 \pm 0.94$ & $4.95 \pm 0.60$ & 0.7738 & \\
\hline IC, liters & $3.35 \pm 0.52$ & $2.85 \pm 0.44$ & $3.07 \pm 0.52$ & $<0.0001$ & $\mathrm{TE}>\mathrm{SY}, \mathrm{TE}>\mathrm{SE}$ \\
\hline ERV, liters & $1.60 \pm 0.59$ & $2.01 \pm 0.69$ & $1.87 \pm 0.48$ & 0.0005 & $\mathrm{TE}<\mathrm{SY}, \mathrm{TE}<\mathrm{SE}$ \\
\hline IRV, liters & $2.63 \pm 0.53$ & $2.14 \pm 0.46$ & $2.34 \pm 0.53$ & $<0.0001$ & $\mathrm{TE}>\mathrm{SY}, \mathrm{TE}>\mathrm{SE}$ \\
\hline FVC, liters & $4.96 \pm 0.68$ & $4.85 \pm 0.82$ & $4.99 \pm 0.64$ & 0.1977 & \\
\hline $\mathrm{FEV}_{1}$, liters & $3.98 \pm 0.55$ & $3.86 \pm 0.68$ & $4.05 \pm 0.57$ & 0.1045 & \\
\hline $\mathrm{FEV}_{1} / \mathrm{FVC}(\%)$ & $80.78 \pm 7.94$ & $79.87 \pm 10.24$ & $81.58 \pm 8.11$ & 0.7726 & \\
\hline $\mathrm{VO}_{2 \max }(\mathrm{ml} / \mathrm{kg} / \mathrm{min})$ & $43.43 \pm 6.45$ & $46.39 \pm 6.75$ & $46.34 \pm 6.80$ & 0.0086 & $\mathrm{SY}>\mathrm{TE}$ \\
\hline $\mathrm{AT}(\mathrm{mL} /(\mathrm{kg} \cdot \mathrm{min}))$ & $23.66 \pm 4.03$ & $25.87 \pm 6.71$ & $24.83 \pm 4.66$ & 0.0676 & \\
\hline Exercise time (sec) & $685.06 \pm 77.65$ & $689.54 \pm 89.78$ & $719.84 \pm 90.81$ & 0.0203 & $\mathrm{SY}>\mathrm{TE}$ \\
\hline $\begin{array}{l}\text { Female } \\
\text { Number of subjects }\end{array}$ & 64 & 46 & 77 & & \\
\hline VT, liters & $0.57 \pm 0.24$ & $0.51 \pm 0.21$ & $0.58 \pm 0.26$ & 0.0844 & \\
\hline VC, liters & $3.52 \pm 0.49$ & $3.19 \pm 0.49$ & $3.44 \pm 0.48$ & 0.0002 & $\mathrm{TE}>\mathrm{SE}, \mathrm{SY}>\mathrm{SE}$ \\
\hline IC, liters & $2.19 \pm 0.38$ & $1.94 \pm 0.35$ & $2.14 \pm 0.39$ & 0.0009 & $\mathrm{TE}>\mathrm{SE}, \mathrm{SY}>\mathrm{SE}$ \\
\hline ERV, liters & $1.35 \pm 0.38$ & $1.25 \pm 0.30$ & $1.30 \pm 0.39$ & 0.2385 & \\
\hline IRV, liters & $1.62 \pm 0.45$ & $1.43 \pm 0.36$ & $1.56 \pm 0.40$ & 0.0681 & \\
\hline FVC, liters & $3.54 \pm 0.52$ & $3.24 \pm 0.47$ & $3.47 \pm 0.47$ & 0.0018 & $\mathrm{TE}>\mathrm{SE}, \mathrm{SY}>\mathrm{SE}$ \\
\hline $\mathrm{FEV}_{1}$, liters & $2.88 \pm 0.46$ & $2.65 \pm 0.48$ & $2.86 \pm 0.47$ & 0.0131 & $\mathrm{TE}>\mathrm{SE}$ \\
\hline $\mathrm{FEV}_{1} / \mathrm{FVC}(\%)$ & $81.60 \pm 8.31$ & $81.79 \pm 8.38$ & $82.55 \pm 8.89$ & 0.8265 & \\
\hline $\mathrm{VO}_{2 \max }(\mathrm{mL} / \mathrm{kg} / \mathrm{min})$ & $34.81 \pm 4.85$ & $36.97 \pm 5.30$ & $38.18 \pm 5.76$ & 0.0012 & $\mathrm{SY}>\mathrm{TE}$ \\
\hline $\mathrm{AT}(\mathrm{mL} /(\mathrm{kg} \cdot \mathrm{min}))$ & $21.03 \pm 3.00$ & $21.48 \pm 3.54$ & $21.57 \pm 3.82$ & 0.6382 & \\
\hline Exercise time (sec) & $585.02 \pm 61.9$ & $580.5 \pm 74.5$ & $618.14 \pm 48.46$ & 0.0006 & $\mathrm{SY}>\mathrm{TE}, \mathrm{SY}>\mathrm{SE}$ \\
\hline
\end{tabular}

Data are presented as the mean \pm standard deviation. $P$ value: ANOVA result. TE: Tae-Eum, SE: So-Eum, SY: So-Yang, VT: tidal volume, VC: vital capacity, IC: inspiratory capacity, ERV: expiratory reserve volume, IRV: inspiratory reserve volume, FVC: forced vital capacity, FEV ${ }_{1}$ : forced expiratory volume in 1 sec, $\mathrm{VO}_{2 \max }$ : maximal oxygen consumption, and AT: anaerobic threshold.

study was to investigate the relationship between pulmonary function and physiological differences among SCTs, especially the TE type.

Gender, age, and height are the major determinants of pulmonary function in normal adults $[30,31]$. It has also been reported that lung function deteriorates with high BMI and obesity [32]. In this study, there were significant differences in height, weight, blood pressure, fasting insulin, and HDL values according to the constitution but no differences in age.
Therefore, we compared the difference of each constitution before and after adjusting for the above variables as covariates.

When comparing the general characteristics according to constitution, participants with the TE type had a higher body weight, BMI, and waist circumference than the other constitutions; thus, high blood pressure, fasting insulin, TGs, and low HDL were confirmed. This is consistent with previous studies that reported that subjects with the TE type 
TABLE 3: Results of the pulmonary function test among Sasang constitutional types (ANCOVA).

\begin{tabular}{|c|c|c|c|c|c|}
\hline Variables & $\mathrm{TE}$ & SE & SY & $P$ value & Post hoc \\
\hline Total (with sex) & 153 & 72 & 166 & & \\
\hline \multicolumn{6}{|l|}{ Number of subjects } \\
\hline VT, liters & $0.63 \pm 0.03$ & $0.63 \pm 0.04$ & $0.67 \pm 0.02$ & 0.4283 & \\
\hline VC, liters & $4.18 \pm 0.05$ & $4.11 \pm 0.07$ & $4.26 \pm 0.04$ & 0.1140 & \\
\hline IC, liters & $2.67 \pm 0.04$ & $2.58 \pm 0.06$ & $2.69 \pm 0.03$ & 0.2174 & \\
\hline ERV, liters & $1.52 \pm 0.05$ & $1.53 \pm 0.06$ & $1.57 \pm 0.04$ & 0.6807 & \\
\hline IRV, liters & $2.04 \pm 0.04$ & $1.95 \pm 0.06$ & $2.02 \pm 0.04$ & 0.4930 & \\
\hline FVC, liters & $4.18 \pm 0.05$ & $4.13 \pm 0.07$ & $4.3 \pm 0.04$ & 0.0195 & \\
\hline $\mathrm{FEV}_{1}$, liters & $3.4 \pm 0.05$ & $3.31 \pm 0.06$ & $3.49 \pm 0.04$ & 0.0214 & $\mathrm{SY}>\mathrm{SE}$ \\
\hline $\mathrm{FEV}_{1} / \mathrm{FVC}(\%)$ & $81.89 \pm 0.84$ & $80.28 \pm 1.15$ & $81.39 \pm 0.68$ & 0.5863 & \\
\hline $\mathrm{VO}_{2 \max }(\mathrm{mL} /(\mathrm{kg} \cdot \min ))$ & $41.06 \pm 0.57$ & $40.06 \pm 0.79$ & $41.56 \pm 0.47$ & 0.2009 & \\
\hline $\mathrm{AT}(\mathrm{mL} /(\mathrm{kg} \cdot \mathrm{min}))$ & $22.89 \pm 0.41$ & $23.14 \pm 0.57$ & $22.98 \pm 0.34$ & 0.9485 & \\
\hline Exercise time (sec) & $653.43 \pm 7.29$ & $618.87 \pm 10.02$ & $663.69 \pm 5.95$ & 0.0002 & $\mathrm{TE}>\mathrm{SE}, \mathrm{SY}>\mathrm{SE}$ \\
\hline Male & 89 & 26 & 89 & & \\
\hline \multicolumn{6}{|l|}{ Number of subjects } \\
\hline VT, liters & $0.69 \pm 0.04$ & $0.78 \pm 0.07$ & $0.74 \pm 0.03$ & 0.4619 & \\
\hline VC, liters & $4.88 \pm 0.07$ & $4.97 \pm 0.13$ & $4.99 \pm 0.07$ & 0.5799 & \\
\hline IC, liters & $3.22 \pm 0.06$ & $3.07 \pm 0.11$ & $3.15 \pm 0.05$ & 0.5758 & \\
\hline ERV, liters & $1.67 \pm 0.06$ & $1.9 \pm 0.12$ & $1.84 \pm 0.06$ & 0.1486 & \\
\hline IRV, liters & $2.53 \pm 0.06$ & $2.29 \pm 0.11$ & $2.4 \pm 0.06$ & 0.2204 & \\
\hline FVC, liters & $4.87 \pm 0.07$ & $4.9 \pm 0.12$ & $5.06 \pm 0.06$ & 0.0930 & \\
\hline $\mathrm{FEV}_{1}$, liters & $3.95 \pm 0.06$ & $3.87 \pm 0.12$ & $4.09 \pm 0.06$ & 0.0892 & \\
\hline $\mathrm{FEV}_{1} / \mathrm{FVC}(\%)$ & $81.51 \pm 1.03$ & $78.96 \pm 1.86$ & $80.93 \pm 0.91$ & 0.5394 & \\
\hline $\mathrm{VO}_{2 \max }(\mathrm{mL} /(\mathrm{kg} \cdot \min ))$ & $45.01 \pm 0.79$ & $44.2 \pm 1.42$ & $45.41 \pm 0.69$ & 0.6851 & \\
\hline $\mathrm{AT}(\mathrm{mL} /(\mathrm{kg} \cdot \mathrm{min}))$ & $24.2 \pm 0.59$ & $25.18 \pm 1.06$ & $24.49 \pm 0.52$ & 0.7638 & \\
\hline Exercise time (sec) & $701.51 \pm 10.57$ & $664.48 \pm 19.1$ & $710.7 \pm 9.34$ & 0.0636 & \\
\hline Female & 64 & 46 & 77 & & \\
\hline \multicolumn{6}{|l|}{ Number of subjects } \\
\hline VT, liters & $0.58 \pm 0.04$ & $0.49 \pm 0.04$ & $0.58 \pm 0.03$ & 0.1555 & \\
\hline VC, liters & $3.42 \pm 0.07$ & $3.23 \pm 0.07$ & $3.46 \pm 0.05$ & 0.0271 & $\mathrm{SY}>\mathrm{SE}$ \\
\hline IC, liters & $2.06 \pm 0.06$ & $2.02 \pm 0.06$ & $2.18 \pm 0.04$ & 0.0373 & \\
\hline ERV, liters & $1.39 \pm 0.06$ & $1.2 \pm 0.06$ & $1.28 \pm 0.04$ & 0.1251 & \\
\hline IRV, liters & $1.49 \pm 0.06$ & $1.53 \pm 0.07$ & $1.6 \pm 0.05$ & 0.3310 & \\
\hline FVC, liters & $3.45 \pm 0.07$ & $3.29 \pm 0.07$ & $3.47 \pm 0.05$ & 0.0823 & \\
\hline $\mathrm{FEV}_{1}$, liters & $2.82 \pm 0.07$ & $2.68 \pm 0.07$ & $2.84 \pm 0.05$ & 0.1580 & \\
\hline $\mathrm{FEV}_{1} / \mathrm{FVC}(\%)$ & $82.05 \pm 1.43$ & $81.5 \pm 1.5$ & $81.96 \pm 1.05$ & 0.9614 & \\
\hline $\mathrm{VO}_{2 \max }(\mathrm{mL} /(\mathrm{kg} \cdot \min ))$ & $37.04 \pm 0.84$ & $35.28 \pm 0.89$ & $37.35 \pm 0.62$ & 0.1232 & \\
\hline $\mathrm{AT}(\mathrm{mL} /(\mathrm{kg} \cdot \mathrm{min}))$ & $21.45 \pm 0.57$ & $21.22 \pm 0.6$ & $21.38 \pm 0.42$ & 0.9663 & \\
\hline Exercise time (sec) & $601.64 \pm 9.79$ & $566.46 \pm 10.31$ & $612.72 \pm 7.17$ & 0.0005 & $\mathrm{SY}>\mathrm{SE}$ \\
\hline
\end{tabular}

Data are presented as the mean \pm standard error. $P$ value: ANCOVA test result. Data are adjusted for sex, age, height, weight, and presence of diabetes mellitus. TE: Tae-Eum, SE: So-Eum, SY: So-Yang, VT: tidal volume, VC: vital capacity, IC: inspiratory capacity, ERV: expiratory reserve volume, IRV: inspiratory reserve volume, FVC: forced vital capacity, $\mathrm{FEV}_{1}$ : forced expiratory volume in $1 \mathrm{sec}, \mathrm{VO}_{2 \max }$ : maximal oxygen consumption, and AT: anaerobic threshold.

are prone to obesity and are therefore vulnerable to metabolic syndrome, hypertension, and diabetes $[6,9]$. The sexually stratified results showed the same tendency. TE type males had significantly higher body weight, BMI, waist circumference, fasting insulin, and TGs and lower HDL values. This tendency was maintained for TE type females, where a higher weight, BMI, blood pressure, waist circumference, fasting insulin, and TGs were distinguished. Considering that these variables distinguished by constitution affect pulmonary function, we took into account parameters such as sex, age, height, weight, and presence of diabetes mellitus as covariates and compared those results with those obtained from oneway ANOVA.

The present study found that, in general, subjects with the TE type exhibit increased pulmonary function and lung volume compared with the other types. Because lung function 
is mostly affected by height [33], a relatively taller height in TE type subjects may explain the difference in pulmonary capacity. Subjects with the TE type had relatively higher FVC and $\mathrm{FEV}_{1}$ values, consistent with previous research that TE type males had a large PFT value [34]. Additionally, the FVC and $\mathrm{FEV}_{1}$ values of subjects with the SE type were the smallest among the SCTs. It is presumed that this result is because the height of SE subjects is significantly smaller than those with the TE and SY types.

After adjusting for age, height, weight, and presence of diabetes mellitus as covariates, there was a tendency towards lower FVC values in TE type males than other constitutions, although the tendency was not significant. These results indicate that innate pulmonary function of the TE type is weaker than that of the other constitutions and that the lung function characteristics of the TE type are not the same as those of a general obese group (i.e., subjects with the TE type have unique characteristics in relation to pulmonary function and $\mathrm{BMI})$.

Previous studies have shown that an increase in BMI is associated with a decrease in FVC and $\mathrm{FEV}_{1}$ [35]. The TE type subjects have a higher BMI than those from the other groups, with an average of over 25, which is considered obese in Korea [36]. Obesity is closely related to decreased lung function, and it is reported that the distribution of body fat affects pulmonary function in particular $[35,37,38]$. Truncal obesity physically reduces the compliance of the chest wall, respiratory muscular strength and function, and the lung volume and peripheral airway size, and abdominal fat affects the thorax and diaphragm to restrict lung expansion [39]. In addition, the inverse association between waist circumference and pulmonary function in the normal, overweight, and obesity groups suggests a risk that pulmonary function may be reduced by this physical mechanism, which is a tendency that results from the increased waist circumference in TE type subjects [40].

In addition, changes in respiratory function in the TE type reflect altered lung volume caused by obesity. It is reported that obesity causes a reduction in the ERV as a result of a reduction in diaphragm mobility and pulmonary compliance [41]. Obesity also contributes to an increase in IRV to compensate the ventilation [42]. IRV was increased in the total TE group, and a reduction in ERV and an increase in IRV were observed in the male TE group. Multiple studies have demonstrated that the effect of obesity on lung function is greater in males than in females, possibly because of gender-related differences in fat distribution [39]. Even after adjusting for possible covariates, this tendency remained in TE type males (not significant). According to ANOVA, $\mathrm{VO}_{2 \max }$ and exercise time also showed the characteristic of decreased cardiopulmonary function in TE type participants compared to the other types. This result suggests that subjects with the TE type exhibit characteristics of obesity; thus, their cardiorespiratory function is reduced [43].

The current study is an analysis of young adult participants. In the case of middle-aged adults reported previously, a reduction of FVC in the TE types had a stronger tendency than in the present study [25]. Taken together, we believe that the TE type causes slightly weaker pulmonary function in young adults and, as age increases, lung function of subjects with the TE type deteriorates more rapidly than those with the other constitutions.

The following points are limitations to present study. First, we recruited participants who were considered healthy and did not perform any other chest X-rays. Second, variables such as factors affecting pulmonary function (smoking, drinking, and exercise) were not considered together. Thus, a more accurate comparison of pulmonary function was limited. In addition, considering the fact that pulmonary function reaches its maximum value in the mid-20's and declines as age increases [44], it is necessary to have a prospective cohort study and cross-sectional studies.

As mentioned above, subjects with the TE type have the highest prevalence of metabolic syndrome and hypertension than those with the other constitutions $[3,6]$. Both metabolic syndrome and pulmonary dysfunction increase the risk of cardiovascular morbidity and mortality [21]. Therefore, for the management of cardiovascular disease, it is necessary to manage and prevent metabolic syndrome with selective PFTs at a relatively young age in people with the TE types.

In conclusion, our data suggest that subjects with the TE type, especially males, exhibit weaker pulmonary function, in terms of lung capacity and volume than those with the SE and SY types.

\section{Data Availability}

Data are available from the Korea Institute of Oriental Medicine (KIOM) Korean Medicine Data Center (KDC, http://kdc.kiom.re.kr/html/, permission number: 20160302) for researchers who meet the criteria for access to confidential data

\section{Conflicts of Interest}

The authors declare that there are no conflicts of interest.

\section{Acknowledgments}

This work was supported by the Bio \& Medical Technology Development Program of the National Research Foundation (NRF) funded by the Ministry of Science, ICT \& Future Planning (nos. 2015M3A9B6027139 and 2015M3A9B6028310).

\section{References}

[1] J. Yoo, E. Lee, C. Kim, J. Lee, and L. Lixing, "Sasang constitutional medicine and traditional Chinese medicine: A comparative overview," Evidence-Based Complementary and Alternative Medicine, vol. 2012, Article ID 980807, 2012.

[2] H. Chae, I. K. Lyoo, S. J. Lee et al., "An alternative way to individualized medicine: psychological and physical traits of Sasang typology," The Journal of Alternative and Complementary Medicine, vol. 9, no. 4, pp. 519-528, 2003.

[3] J. Lee, J. Lee, E. Lee, J. Yoo, Y. Kim, and B. Koh, "The sasang constitutional types can act as a risk factor for hypertension," Clinical and Experimental Hypertension, vol. 33, no. 8, pp. 525532, 2011. 
[4] T.-G. Lee, B. Koh, and S. Lee, "Sasang constitution as a risk factor for diabetes mellitus: a cross-sectional study," EvidenceBased Complementary and Alternative Medicine, vol. 6, no. 1, pp. 99-103, 2009.

[5] K. Choi, J. Lee, J. Yoo, E. Lee, B. Koh, and J. Lee, "Sasang constitutional types can act as a risk factor for insulin resistance," Diabetes Research and Clinical Practice, vol. 91, no. 3, pp. e57e60, 2011.

[6] K. H. Song, S.-G. Yu, and J. Y. Kim, "Prevalence of metabolic syndrome according to sasang constitutional medicine in Korean subjects," Evidence-Based Complementary and Alternative Medicine, vol. 2012, Article ID 646794, 8 pages, 2012.

[7] T.-G. Lee, S.-K. Lee, B.-K. Choi, and I.-B. Song, "A study on the prevalences of chronic diseases according to Sasang constitution at a health examination center," Journal of Sasang Constitutional Medicine, vol. 17, no. 2, pp. 32-45, 2005.

[8] H.-Y. Lee, W.-J. Lee, H.-W. Kim et al., "A systematic review on Sasang constitutional type-associated susceptibility to disorders in Korea," The Journal of Alternative and Complementary Medicine, vol. 22, no. 12, pp. 950-956, 2016.

[9] E. Jang, Y. Baek, K. Park, and S. Lee, "Could the Sasang constitution itself be a risk factor of abdominal obesity?" BMC Complementary and Alternative Medicine, vol. 13, pp. 72-77, 2013.

[10] J. Y. Kim and D. D. Pham, "Sasang constitutional medicine as a holistic tailored medicine," Evidence-Based Complementary and Alternative Medicine, vol. 6, supplement 1, pp. 11-19, 2009.

[11] E. B. Shim, S. W. Lee, J. Y. Kim, C. H. Leem, and Y. E. Earm, "Taeeum-type people in Sasang constitutional medicine have a reduced mitochondrial metabolism," Integrative Medicine Research, vol. 1, no. 1, pp. 41-45, 2012.

[12] E. B. Shim, C. H. Leem, J. J. Kim, and J. Y. Kim, "Lower cellular metabolic power can be an explanation for obesity trend in Tae-Eum type: hypothesis and clinical observation," Integrative Medicine Research, vol. 6, no. 3, pp. 254-259, 2017.

[13] H. K. Kim, H. Lee, J. H. So et al., "Energy metabolism and whole-exome sequencing-based analysis of Sasang constitution: a pilot study," Integrative Medicine Research, vol. 6, no. 2, pp. 165-178, 2017

[14] R. Pellegrino, G. Viegi, V. Brusasco et al., "Interpretative strategies for lung function tests," European Respiratory Journal, vol. 26, no. 5, pp. 948-968, 2005.

[15] T. J. Barreiro and I. Perillo, "An Approach to Interpreting Spirometry," American Family Physician, vol. 69, no. 5, pp. 11071114, 2004.

[16] G. Engström, P. Lind, B. Hedblad et al., "Lung function and cardiovascular risk relationship with inflammation-sensitive plasma proteins," Circulation, vol. 106, no. 20, pp. 2555-2560, 2002.

[17] A. K. Johnston, D. M. Mannino, G. W. Hagan, K. J. Davis, and V. A. Kiri, "Relationship between lung function impairment and incidence or recurrence of cardiovascular events in a middleaged cohort," Thorax, vol. 63, no. 7, pp. 599-605, 2008.

[18] O. B. Margretardottir, S. J. Thorleifsson, G. Gudmundsson et al., "Hypertension, systemic inflammation and body weight in relation to lung function impairmentan epidemiological study," Copd-Journal of Chronic Obstructive Pulmonary Disease, vol. 6, no. 4, pp. 250-255, 2009.

[19] M. D. Goldman, "Lung dysfunction in diabetes," Diabetes Care, vol. 26, no. 6, pp. 1915-1918, 2003.
[20] D. J. Cirillo, Y. Agrawal, and P. A. Cassano, "Lipids and pulmonary function in the Third National Health and Nutrition Examination Survey," American Journal of Epidemiology, vol. 155, no. 9, pp. 842-848, 2002.

[21] N. Leone, D. Courbon, F. Thomas et al., "Lung function impairment and metabolic syndrome the critical role of abdominal obesity," American Journal of Respiratory and Critical Care Medicine, vol. 179, no. 6, pp. 509-516, 2009.

[22] Y.-J. Paek, K.-S. Jung, Y.-I. Hwang, K.-S. Lee, D. R. Lee, and J.-U. Lee, "Association between low pulmonary function and metabolic risk factors in Korean adults: The Korean National Health and Nutrition Survey," Metabolism - Clinical and Experimental, vol. 59, no. 9, pp. 1300-1306, 2010.

[23] W.-K. Jung, J.-S. Yoo, S.-B. Koh, and J.-K. Park, "Correlation of Sasang constitution and chronic obstructive pulmonary disease," Journal of Sasang Constitutional Medicine, vol. 22, no. 3, pp. 98-109, 2010.

[24] Y. Pak, J. Kim, J. Lee, E. Lee, and B. Koh, "Association between Sasang Constitution, Impaired Lung Function and Metabolic Syndrome among Middle-aged Adults in Korea," Journal of Sasang Constitutional Medicine, vol. 25, no. 3, pp. 180-194, 2013.

[25] S. K. Lee, D. W. Yoon, K. S. Kim et al., "Assessment of Pulmonary Function Among Sasang Constitutional Types: A populationbased study in Korea," Integrative Medicine Research, vol. 4, no. 1, p. 96, 2015.

[26] J.-H. Do, E. Jang, B. Ku, J.-S. Jang, H. Kim, and J. Y. Kim, “Development of an integrated Sasang constitution diagnosis method using face, body shape, voice, and questionnaire information," BMC Complementary and Alternative Medicine, vol. 12, article 85, 2012.

[27] J. Yoon, J. Nam, C. H. Leem, and J. Y. Kim, "Body composition and personality traits in so-Yang type males," BMC Complementary and Alternative Medicine, vol. 17, no. 1, article no. 417, 2017.

[28] M. R. Miller, J. Hankinson, V. Brusasco et al., "Standardisation of spirometry," European Respiratory Journal, vol. 26, no. 2, pp. 319-338, 2005.

[29] K. M. Michael, J. K. Allen, and R. F. MacKo, "Reduced ambulatory activity after stroke: the role of balance, gait, and cardiovascular fitness," Archives of Physical Medicine and Rehabilitation, vol. 86, no. 8, pp. 1552-1556, 2005.

[30] R. I. Harik-Khan, R. A. Wise, and J. L. Fleg, "The effect of gender on the relationship between body fat distribution and lung function," Journal of Clinical Epidemiology, vol. 54, no. 4, pp. 399-406, 2001.

[31] J. A. Neder, S. Andreoni, A. Castelo-Filho, and L. E. Nery, "Reference values for lung function tests. I. Static volumes," Brazilian Journal of Medical and Biological Research, vol. 32, no. 6, pp. 703-717, 1999.

[32] C. Zammit, H. Liddicoat, I. Moonsie, and H. Makker, "Obesity and respiratory diseases," Journal of General Internal Medicine, vol. 3, pp. 335-343, 2010.

[33] S. Ostrowski and W. Barud, "Factors influencing lung function: are the predicted values for spirometry reliable enough?" Journal of Physiology and Pharmacology, vol. 57, no. 4, pp. 263271, 2006.

[34] H. Lee, "The study of the differences in pulmonary function of men based on the Sasang Constitution," Master's thesis, Kyung Hee University, 2012.

[35] K. Parameswaran, D. C. Todd, and M. Soth, "Altered respiratory physiology in obesity," Canadian Respiratory Journal, vol. 13, no. 4, pp. 203-210, 2006. 
[36] S. W. Oh, "Obesity and metabolic syndrome in Korea," Diabetes \& Metabolism, vol. 35, no. 6, pp. 561-566, 2011.

[37] S. W. Littleton, "Impact of obesity on respiratory function," Respirology, vol. 17, no. 1, pp. 43-49, 2012.

[38] L. C. Collins, P. D. Hoberty, J. F. Walker, E. C. Fletcher, and A. N. Peiris, "The effect of body fat distribution on pulmonary function tests," CHEST, vol. 107, no. 5, pp. 1298-1302, 1995.

[39] K. M. McClean, F. Kee, I. S. Young, and J. S. Elborn, "Obesity and the lung: 1 Epidemiology," Thorax, vol. 63, no. 7, pp. 649654, 2008.

[40] Y. Chen, D. Rennie, Y. F. Cormier, and J. Dosman, "Waist circumference is associated with pulmonary function in normalweight, overweight, and obese subjects," American Journal of Clinical Nutrition, vol. 85, no. 1, pp. 35-39, 2007.

[41] S. M. Koenig, "Pulmonary complications of obesity," The American Journal of the Medical Sciences, vol. 321, no. 4, pp. 249-279, 2001.

[42] D. Costa, M. C. Barbalho, G. P. S. Miguel, E. M. P. Forti, and J. L. M. C. Azevedo, "The impact of obesity on pulmonary function in adult women," Clinics, vol. 63, no. 6, pp. 719-724, 2008.

[43] P. Setty, B. V. Padmanabha, and B. R. Doddamani, "Correlation between obesity and cardio respiratory fitness," International Journal of Medical Science and Public Health, vol. 2, no. 3, pp. 300-304, 2013.

[44] K. Pinkerton and R. Harding, The lung: development, aging and the environment, Elsevier, aging and the environment, 2014. 


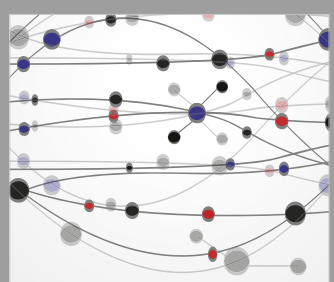

The Scientific World Journal
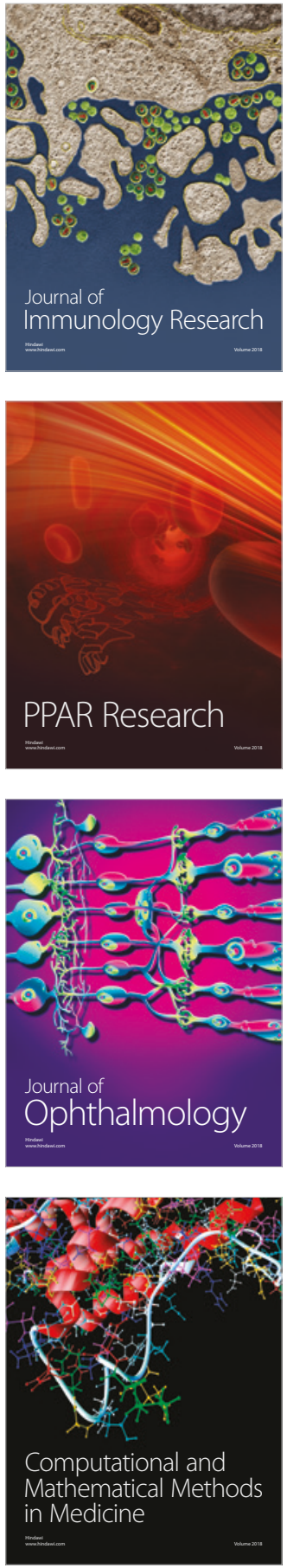

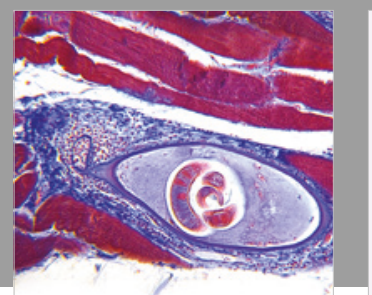

Gastroenterology Research and Practice

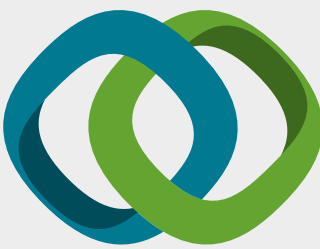

\section{Hindawi}

Submit your manuscripts at

www.hindawi.com
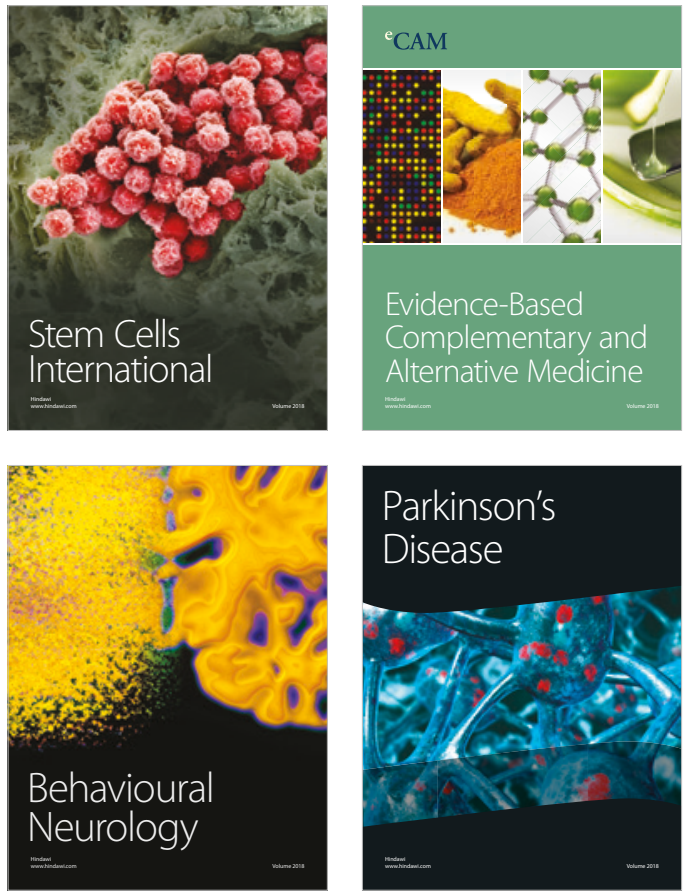

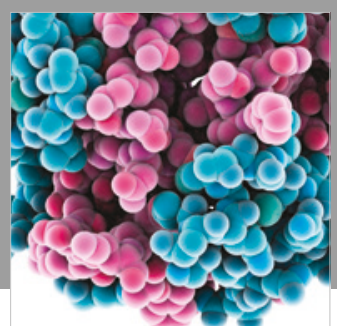

ournal of

Diabetes Research

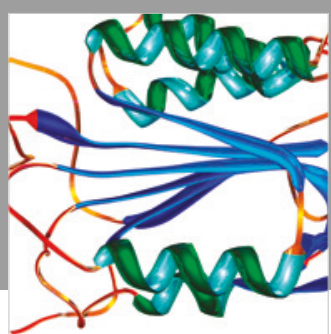

Disease Markers
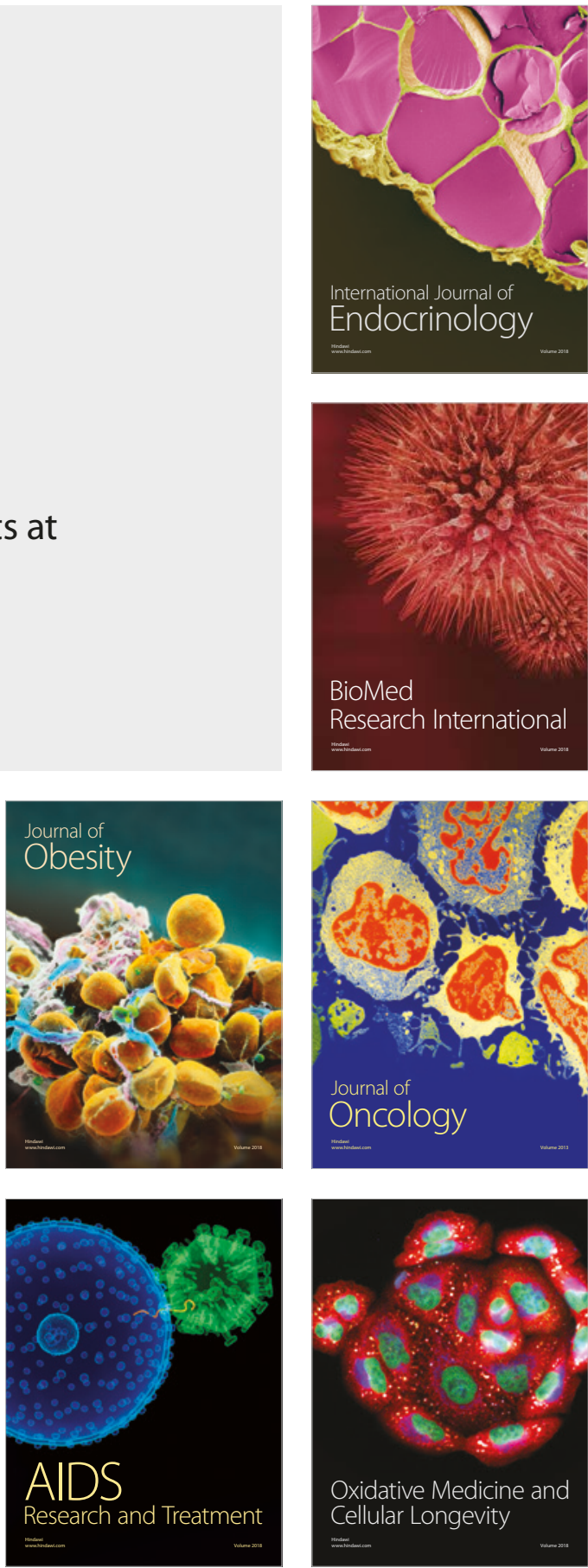